Pacific Journal of Mathematic 


\title{
THE NUMBER OF SOLUTIONS OF CERTAIN TYPES OF EQUATIONS IN A FINITE FIELD
}

\author{
L. CARLit Z
}

1. Using a very simple principle, Morgan Ward [3] indicated how one can obtain all solutions of the equation

$$
y^{m}=f\left(x_{1}, \cdots, x_{r}\right) \quad\left(y, x_{i} \in F\right),
$$

where $F$ is an arbitrary field, $f\left(x_{1}, \cdots, x_{r}\right)$ is a homogeneous polynomial of degree $n$ with coefficients in $F$, and $(m, n)=1$. The same principle had been applied earlier to a special equation by Hua and Vandiver [2]. If this principle is applied in the case of a finite field $F$ we readily obtain the total number of solutions of equations of the type (1). Somewhat more generally, let

$$
f_{i}\left(x_{i}\right)=f_{i}\left(x_{i 1}, \cdots, x_{i s_{i}}\right) \quad(i=1, \cdots, r)
$$

denote $r$ polynomials with coefficients in $G F(q)$, and assume

$$
f_{i}\left(\lambda x_{1}, \cdots, \lambda x_{s_{i}}\right)=\lambda^{m_{i}} f_{i}\left(x_{1}, \cdots, x_{s_{i}}\right) \quad(\lambda \in G F(q))
$$

assume also

$$
\left(m, m_{i}, q-1\right)=1 \quad(i=1, \cdots, r) .
$$

We consider the equation

$$
y^{m}=f_{1}\left(x_{11}, \cdots, x_{1 s_{1}}\right)+\cdots+f_{r}\left(x_{r 1}, \cdots, x_{r s_{r}}\right)
$$

in $s_{1}+\cdots+s_{r}+1$ unknowns.

Suppose first we have a solution of (4) with $y \neq 0$. Select integers $h, k, l$ such that

$$
h m+k m_{1} m_{2} \cdots m_{r}+l(q-1)=1, \quad(h, q-1)=1 ;
$$

Received August 8, 1953.

Pacific J. Math. 5 (1955), 177-181 
this can be done in view of (3). Next put

$$
y=\lambda^{h}, x_{i j}=\lambda^{k M / m_{i}} z_{i j} \quad\left(M=m_{1} m_{2} \cdots m_{r}\right) .
$$

Substituting in (4) and using (2), we get

$$
\lambda^{h m}=\lambda^{k M}\left\{f_{1}\left(z_{1}\right)+\cdots+f_{r}\left(z_{r}\right)\right\} .
$$

Since $\lambda^{q-1}=1$, it is clear from (5) that

$$
\lambda=f_{1}\left(z_{1}\right)+\cdots+f_{r}\left(z_{r}\right) .
$$

Thus any solution $\left(y, x_{i j}\right)$ of $(4)$ with $y \neq 0$ can be obtained from (6) and (7) by assigning arbitrary values to $z_{i j}$ such that the right member of $(7)$ does not vanish. Let $N$ denote the total number of solutions of $(4)$ and let $N_{0}$ denote the number of solutions with $y=0$. Thus there are $N-N_{0}$ sets $z_{i j}$ for which $\lambda \neq 0$. Since in all there are $q^{s_{1}+\cdots+s_{r}}$ sets $z_{i j}$ it follows that

$$
N=q^{s_{1}+\cdots+s_{r}} .
$$

This proves:

THEOREM. Let the polynomials $f_{i}$ satisfy (2) and (3). Then the total number of solutions of (4) is furnished by (8).

2. In Theorem II of [2] Hua and Vandiver proved that the number of solutions of

$$
c_{1} x_{1}^{a_{1}}+c_{2} x_{2}^{a_{2}}+\cdots+c_{s} x_{s}^{a_{s}}=0
$$

subject to the conditions

$$
c_{1} c_{2} \cdots c_{s} x_{1} x_{2} \cdots x_{s} \neq 0,\left(a_{i}, q-1\right)=k_{i},\left(k_{i}, k_{j}\right)=1 \text { for } i \neq j,
$$

is equal to

$$
\frac{q-1}{q}\left\{(q-1)^{s-1}+(-1)^{s}\right\} \text {. }
$$

It is easy to show that (10) implies that the total number of solutions of (9) is equal to $q^{s-1}$, which agrees with (8). Conversely if $N_{s}$ denotes the number of nonzero solutions of $(9)$, and we assume that 


$$
\left(k_{i}, k_{j}\right)=1 \quad(i, j=1, \cdots, s ; i \neq j),
$$

then using (8) we get

$$
q^{s-1}=N_{s}+\left(\begin{array}{l}
s \\
1
\end{array}\right) N_{s-1}+\left(\begin{array}{l}
s \\
2
\end{array}\right) N_{s-2}+\cdots+\left(\begin{array}{c}
s \\
s-1
\end{array}\right) N_{1}+1 .
$$

Hence (if we take $N_{0}=1$ )

$$
\begin{aligned}
(q-1)^{s} & =\sum_{r=1}^{s}(-1)^{s-r}\left(\begin{array}{l}
s \\
r
\end{array}\right) q \sum_{t=0}^{r}\left(\begin{array}{l}
r \\
t
\end{array}\right) N_{t}+(-1)^{s} \\
& =q \sum_{r=0}^{s}(-1)^{s-r}\left(\begin{array}{l}
s \\
r
\end{array}\right) \sum_{t=0}^{r}\left(\begin{array}{l}
r \\
t
\end{array}\right) N_{t}-(-1)^{s}(q-1) \\
& =q \sum_{t=0}^{s}\left(\begin{array}{l}
s \\
t
\end{array}\right) N_{t} \sum_{r=t}^{s}(-1)^{s-r}\left(\begin{array}{l}
s-t \\
s-r
\end{array}\right)-(-1)^{s}(q-1) \\
& =q N_{s}-(-1)^{s}(q-1),
\end{aligned}
$$

and (10) follows at once. Thus if we assume (11) then (8) and (10) are equivalent.

If in place of (11) we assume only that

$$
\left(k_{1}, k_{2} k_{3} \cdots k_{s}\right)=1 \text {, }
$$

the situation is somewhat different. As above let $N_{s}$ denote the number of nonzero solutions of (9), and let $M_{s-1}$ denote the total number of solutions $x_{2}, \cdots, x_{s}$ of

$$
c_{2} x_{2}^{a_{2}}+c_{3} x_{3}^{a_{3}}+\cdots+c_{s} x_{s}^{a_{s}}=0 .
$$

Using (8) we now get

$$
q^{s-1}=M_{s-1}+N_{s}+\left(\begin{array}{c}
s-1 \\
1
\end{array}\right) N_{s-1}+\cdots+\left(\begin{array}{c}
s-1 \\
s-1
\end{array}\right) N_{1},
$$

which implies ( with $M_{0}=1$ ) 


$$
(q-1)^{s-1}=\sum_{r=0}^{s-1}(-1)^{s-1-r}\left(\begin{array}{c}
s-1 \\
r
\end{array}\right) M_{r}+N_{s}
$$

Thus making only the assumption (12) we see how the number of solutions of (13) can be expressed in terms of $N_{s}$ and vice versa.

3. Returning to equation (4), we see that a similar result can be obtained if we allow $f_{i}$ to contain additional unknowns:

$$
f_{i}\left(x_{i} ; u_{i}\right)=f_{i}\left(x_{i 1}, \cdots, x_{i s_{i}} ; u_{i 1}, \cdots, u_{i t_{i}}\right) \text {, }
$$

and assume that (2) holds only for the $x$ 's. Then the number of solutions ( $y$, $\left.x_{i j}, u_{h k}\right)$ of (4) becomes

$$
q^{s_{1}+\cdots+s_{r}+t_{1}+\cdots+t_{r}}
$$

Similarly we may replace the left member of (4) by

$$
y_{1}^{a_{1}} y_{2}^{a_{2}} \cdots y_{s}^{a_{s}} \quad\left(a_{1}, a_{2}, \cdots, a_{s}\right)=m \text {. }
$$

Then assuming ( 3 ) we again find that the number of solutions of the modified equation is equal to

$$
q^{s_{1}+\cdots+s_{r}+s-1}
$$

This kind of generalization lends itself well to equation (9). For example it is easy to show (see [1, Theorem 10]) that the total number of solutions of the equation

$$
\sum_{i=1}^{t} c_{i} \prod_{j=1}^{k_{i}} x_{i j}^{a_{i j}}=0,
$$

subject to $\left(a_{i 1}, \cdots, a_{i k_{i}}, q-1\right)=d_{i},\left(d_{i}, d_{j}\right)=1$ for $i \neq j$, is equal to

$$
q^{k_{1}+\cdots+k^{-1}}
$$

\section{REFERENCE}

1. L. Carlitz, The number of solutions of certain equations in a finite field, Proc. Nat. Acad. Sci. U.S.A. 38 (1952), 515-519. 
2. L. K. Hua and H.S. Vandiver, On the nature of the solutions of certain equations in a finite field, Proc. Nat. Acad. Sci. U.S.A. 35 (1949), 481 - 487.

3. Morgan Ward, A class of soluble diophantine equations, Proc. Nat. Acad. Sci. U.S.A. 37 (1951), $113-114$.

DUKE UNIVERSITY 



\section{PACIFIC JOURNAL OF MATHEMATICS}

\section{EDITORS}

\author{
H. L. ROYDEN \\ Stanford University \\ Stanford, California \\ E. Hewitt \\ University of Washington \\ Seattle 5 , Washington
}

R. P. Dilworth

California Institute of Technology Pasadena 4, California

A. HorN*

University of California

Los Angeles 24, California

\section{ASSOCIATE EDITORS}

\author{
H. BUSEMANN \\ HERBERT FEDERER \\ MARSHALL HALL
}

\author{
P. R. HALMOS \\ HEINZ HOPF
}

ALFRED HORN
R. D. JAMES

BORGE JESSEN

PAUL LÉVY
GEORGE PÓLYA

J. J. STOKER

KOSAKU YOSIDA

\section{SPONSORS}

UNIVERSITY OF BRITISH COLUMBIA

CALIFORNIA INSTITUTE OF TECHNOLOGY

UNIVERSITY OF CALIFORNIA, BERKELEY

UNIVERSITY OF CALIFORNIA, DAVIS

UNIVERSITY OF CALIFORNIA, LOS ANGELES

UNIVERSITY OF CALIFORNIA, SANTA BARBARA

MONTANA STATE UNIVERSITY

UNIVERSITY OF NEVADA

OREGON STATE COLLEGE

UNIVERSITY OF OREGON

UNIVERSITY OF SOUTHERN CALIFORNIA

\author{
STANFORD RESEARCH INSTITUTE \\ STANFORD UNIVERSITY \\ UNIVERSITY OF UTAH \\ WASHINGTON STATE COLLEGE \\ UNIVERSITY OF WASHINGTON
}

AMERICAN MATHEMATICAL SOCIETY HUGHES AIRCRAFT COMPANY SHELL DEVELOPMENT COMPANY

Mathematical papers intended for publication in the Pacific Journal of Mathematics should be typewritten (double spaced), and the author should keep a complete copy. Manuscripts may be sent to any of the editors. Manuscripts intended for the outgoing editors should be sent to their successors. All other communications to the editors should be addressed to the managing editor, Alfred Horn at the University of California, Los Angeles 24, California.

50 reprints of each article are furnished free of charge; additional copies may be obtained at cost in multiples of 50 .

The Pacific Journal of Mathematics is published quarterly, in March, June, September, and December. The price per volume (4 numbers) is $\$ 12.00$; single issues, $\$ 3.50$. Back numbers are available. Special price to individual faculty members of supporting institutions and to individual members of the American Mathematical Society: $\$ 4.00$ per volume; single issues, $\$ 1.25$.

Subscriptions, orders for back numbers, and changes of address should be sent to Pacific Journal of Mathematics, c/o University of California Press, Berkeley 4, California.

Printed at Kokusai Bunken Insatsusha (International Academic Printing Co., Ltd.), No. 10, 1-chome, Fujimi-cho, Chiyoda-ku, Tokyo, Japan.

* During the absence of E. G. Straus.

PUBLISHED BY PACIFIC JOURNAL OF MATHEMATICS, A NON-PROFIT CORPORATION COPYRIGHT 1955 BY PACIFIC JOURNAL OF MATHEMATICS 


\section{Pacific Journal of Mathematics}

\section{Vol. 5, No. $2 \quad$ October, 1955}

Leonard M. Blumenthal, An extension of a theorem of Jordan and von

Neumann ........................................ 161

L. Carlitz, Note on the multiplication formulas for the Jacobi elliptic functions.......................................... 169

L. Carlitz, The number of solutions of certain types of equations in a finite

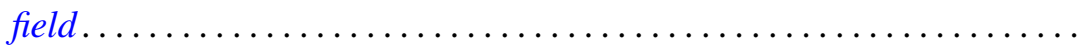

George Bernard Dantzig, Alexander Orden and Philip Wolfe, The generalized simplex method for minimizing a linear form under linear

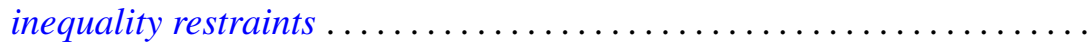

Arthur Pentland Dempster and Seymour Schuster, Constructions for poles and polars in n-dimensions . . . . . . . . . . . . . . . . . . . . 197

Franklin Haimo, Power-type endomorphisms of some class 2 groups ...... 201

Lloyd Kenneth Jackson, On generalized subharmonic functions ......... 215

Samuel Karlin, On the renewal equation ...................... 229

Frank R. Olson, Some determinants involving Bernoulli and Euler numbers of higher order................................ 259

R. S. Phillips, The adjoint semi-group ........................ 269

Alfred Tarski, A lattice-theoretical fixpoint theorem and its applications ... 285

Anne C. Davis, A characterization of complete lattices .............. 311 